\title{
Are health risk attitude and general risk attitude associated with healthcare utilization, costs and working ability? Results from the German KORA FF4 cohort study
}

Johanna I. Lutter ${ }^{1,2^{*}}$ D. Boglárka Szentes ${ }^{1}$, Margarethe E. Wacker ${ }^{1}$, Joachim Winter ${ }^{3}$, Sebastian Wichert ${ }^{4}$, Annette Peters ${ }^{5}$, Rolf Holle ${ }^{1}$ and Reiner Leidl ${ }^{1,6}$

\begin{abstract}
Background: Risk attitudes influence decisions made under uncertainty. This paper investigates the association of risk attitudes with the utilization of preventive and general healthcare services, work absence and resulting costs to explore their contribution to the heterogeneity in utilization.

Methods: Data of 1823 individuals ( $56.5 \pm 9.5$ years), participating in the German KORA FF4 population-based cohort study (2013/2014) were analyzed. Individuals' general and health risk attitude were measured as willingness to take risk (WTTR) on 11-point scales. Utilization of preventive and medical services and work absence was assessed and annual costs were calculated from a societal perspective. Generalized linear models with log-link function (logistic, negative-binomial and gamma regression) adjusted for age, sex, and height were used to analyze the association of WTTR with the utilizations and costs.

Results: Higher WTTR was significantly associated with lower healthcare utilization (physician visits, physical therapy, and medication intake), work absence days and indirect costs. Regarding preventive services, an overall negative correlation between WTTR and utilization was examined but this observation remained non-significant except for the outcome medical check-up. Here, higher WTTR was significantly associated with a lower probability of participation. For all associations mentioned, Odds Ratios ranged between 0.90 and 0.79 , with $p<0.05$. Comparing the two risk attitudes (general and regarding health) we obtained similar results regarding the directions of associations.

Conclusions: We conclude that variations in risk attitudes contribute to the heterogeneity of healthcare utilization. Thus, knowledge of their associations with utilization might help to better understand individual decision-making especially in case of participation in preventive services.
\end{abstract}

Keywords: Willingness to take risk, Healthcare utilization, Healthcare costs, Prevention, Population-based, Work absence

\footnotetext{
* Correspondence: johanna.lutter@helmholtz-muenchen.de

${ }^{1}$ Helmholtz Zentrum München, German Research Center for Environmental Health $(\mathrm{GmbH})$, Institute of Health Economics and Health Care Management, Ingolstaedter Landstr 1, 85764 Neuherberg, Germany

${ }^{2}$ Ludwig-Maximilians-Universität München, Institute for Medical Informatics,

Biometry and Epidemiology, Marchioninistr 15, 81377 Munich, Germany

Full list of author information is available at the end of the article
}

(c) The Author(s). 2019 Open Access This article is distributed under the terms of the Creative Commons Attribution 4.0 International License (http://creativecommons.org/licenses/by/4.0/), which permits unrestricted use, distribution, and reproduction in any medium, provided you give appropriate credit to the original author(s) and the source, provide a link to the Creative Commons license, and indicate if changes were made. 


\section{Background}

Risk attitude (RA) is a key determinant of decision-making. Especially medical decisions often involve a certain amount of risk and uncertainty, which is why research on RAs is of increasing importance within health economics.

Already intensively investigated in the economic setting, theoretical concepts, measurement techniques and determinants of RA have been developed and reported. Instruments to measure RA include lotteries, assessing hypothetical or actual behavior and self-reports based on situational questions and rating scales $[1,2]$.

According to previous studies, people's attitude towards risk strongly depends on the specific setting, in which the decision has to be made. Thus, a person can have different RAs depending on whether he or she is faced with a financial decision, a decision or action concerning his or her health or any other domain [3]. Furthermore, several determinants of RAs have been identified. According to numerous corresponding reports, age and gender affect RAs with older people and women being more risk averse [4-7]. Dohmen et al. [8] reported height (the taller the more willing to take risks) and parental education (higher risk tolerance for higher parental education) as additional exogenous determinants. Thereafter, these two determinants were included in other studies to further investigate height and parental education as being exogenous determinants $[9,10]$.

Efforts have been undertaken to adapt the measuring instruments and concepts of RAs acquired in economic research and especially in decision theory to the health sector $[11,12]$. In the context of health service research, previous studies analyzed the influence of RAs on health insurance demand [13], treatment choices [14, 15], behavioral health risks such as smoking, alcohol consumption and seat belt none-use [16] and physicians' medical decision-making [17-19]. Decker et al. [20] analyzed the influence of health shocks on willingness to take risks and found a significant increase of risk aversion for those people who suffered from a health shock. This finding is in contrast with the previous assumption that RAs remain constant over lifetime [21].

Adding to the increasing importance of research on RAs in the field of health economics, this study addresses another open question concerning the role of RAs in context of demand for healthcare services. While there are some speculations in the literature, that RAs may affect the use of preventive services and medical care [16], the association is up to now unexamined. We aim to bridge this gap by analyzing the association of RAs with healthcare utilization and related costs. RA has been measured as self-reported willingness to take risk (WTTR) on 11-point scales as has been previously done by Dohmen et al. [8] [22], and further on by Decker et al. [20], Massin et al. [19], Van Der Pol et al. [23], and in a global study of economic preferences, by Falk et al. [24].

The paper has been organized according to the predefined hypotheses:

(i) Higher WTTR is associated with less participation in preventive services such as screening interventions and medical check-up programs, thus taking eventual health risks linked to late discovery of disease amenable to early intervention.

(ii) Higher WTTR is associated with lower general healthcare utilization and associated direct costs, thus taking eventual health risks linked to gaps in treatment initiation or adherence.

Following an explorative approach, we additionally examine the association of WTTR and indirect costs (work absence and early retirement) in a working-age sub cohort to fully investigate all components of disease related costs.

The directions of the hypotheses were further motivated by the general observation that healthcare utilization and costs increase with higher age, and by studies showing that higher age and risk tolerance are negatively correlated $[5,7,25]$. While there are some hints that RAs may vary in individuals over life time [20], we only take a cross-sectional view in this paper.

\section{Methods}

\section{Data and study design}

Data were taken from the population-based study KORA FF4 study (June 2013 to September 2014), the second follow-up of the KORA S4 study conducted in the city of Augsburg and two surrounding counties in southern Germany. Randomly drawn from the target population (adults aged 25-74 with German nationality) using population registries, 4261 subjects participated in the baseline survey S4 (1999-2001). Of those, 2279 participants aged 39 to 85 took part in the 14-year follow-up FF4 study. Detailed information about the study design, sampling methods, response rates and dropouts have been published elsewhere [26, 27]. Since only participants aged 73 and younger answered the RA questions, 428 (18.8\%) participants were excluded from the present analysis. Furthermore, 28 observations had to be excluded due to missing data in the RA variables and variable height. Finally, data of 1823 participants aged 39 to 73 were included in the present cross-sectional analysis.

\section{Ascertainment of risk attitudes}

In order to measure RAs, participants were asked to rate their general willingness to take risk (G-WTTR) on an 11-point scale with 0 indicating 'not at all willing to take risk' and 10 'very willing to take risk'. Additionally, 
people's willingness to take risk in six different domains of life (car driving, financial matters, sports and leisure, career, health, and faith in foreign people) was assessed using the same scale. The present analysis focuses on WTTR in general and regarding health (G-WTTR and H-WTTR) only, even though WTTR in relation to car driving or sports and leisure would also be conceivable in the context of health. The order of questions was chosen in accordance with the original version of the German Socio-Economic Panel (SOEP) where the G-WTTR is assessed first followed by the subdomains including $\mathrm{H}$ WTTR. Dohmen et al. [8] confirmed the behavioral validity of this RA measurement technique by comparing the reported scale values to paid lottery choices acquired in a field experiment. To obtain comparable estimates for GWTTR and H-WTTR in the regression analyses, we use a $\mathrm{z}$-standardized version of the risk measures with mean $=0$ and standard deviation $(\mathrm{SD})=1$.

\section{Measurement of covariates}

Information on all covariates was collected in questionnaires or standardized interviews carried out by trained medical interviewers. Variables have been defined as follows: Social class by Helmert et al. [28] (an additive index of the variables 'household net income', 'educational level' and 'occupational status' that takes values between 1 and 27 with higher values indicating higher social class). Comorbidity (binary variable with 0 : no comorbidity, 1: at least one of the following diseases: hypertension, diabetes, angina pectoris, stroke, cancer, which are known as prevalent diseases with high economic and patient relevant impact). Smoking status (current-, former- and never-smoker [29]). Alcohol consumption (binary variable with low risk: average daily alcohol intake $\leq 12 \mathrm{~g}$ for women and $\leq 24 \mathrm{~g}$ for men and elevated risk: average daily alcohol intake $>12 \mathrm{~g}$ for women and $>24 \mathrm{~g}$ for men [30]). Physical activity (binary variable with the characteristics active: regular sports in leisure time in summer and winter for $\geq 1 \mathrm{~h}$ per week, and inactive: $<1 \mathrm{~h}$ of sports per week).

\section{Assessment of preventive and medical service utilization}

Participants were asked whether they have ever participated in a screening program (namely as programs to detect skin-, lung-, and colon cancer as well as breastand cervical cancer for women and prostate cancer for men) or in a general medical check-up for the early identification of cardiovascular diseases.

Utilization of medical services was assessed using different time horizons with the last 7 days prior to the examination for use of pharmaceuticals, 3 months for the numbers of outpatient physician visits (subdivided into 15 groups of medical specialists excluding dentists [29]) and 12 months for hospital visits (numbers of outpatient hospital treatments and inpatient hospital days), visits to alternative practitioners, physical therapy treatments and rehabilitation stays. Assuming constant utilization, all data were extrapolated to 1 year in order to estimate general healthcare utilization within the last 12 months.

\section{Costs calculation \\ Direct costs}

In Germany, costs of almost all healthcare services (except "out-of-pocket" expenditures e.g. for pharmacies) are covered by German statutory health insurance, which raises income-related insurance contributions. To estimate annual total direct medical costs, which represent a summary measure of the single healthcare utilization categories, we multiplied the reported utilizations with German unit costs (price year 2013) provided by Bock et al. [31]. An overview of all applied unit costs is available in Additional file 1: S1. Unit costs for physician visits varied between $19.36 €$ (for dermatologist) and $78.53 €$ (for psychotherapist) per contact. In case participants reported a physician visit in the previous 3 months without indicating the frequency $(n=2)$, one visit was imputed to follow a conservative approach.

Inpatient and outpatient hospital treatments were priced with $623.18 €$ and $46.80 €$ per day, respectively. We assessed $1408.22 €$ per day spent in the intensive care unit. For each day of inpatient rehabilitation we calculated $125.71 €$ and $62.36 €$ for outpatient rehabilitation. Costs for physical therapy treatment were rated with $17.04 €$ per visit. As Bock et al. [31] did not provide unit costs for alternative practitioner visits, costs were requested directly through the questionnaire. We imputed the average costs per visit $(83 €)$, if participants stated an alternative practitioner visit without specifying resulting costs $(n=2)$.

The calculation of drug costs was restricted to prescription drugs only and based on information on name, pharmaceutical registration number and patient reported dosage of intake during the past week and combined with the pharmacy retail prices provided by the Scientific Institute of the AOK health insurance (WIdO [32]).

The calculation of direct annual costs did not include costs of preventive medical examinations.

\section{Indirect costs}

Annual indirect costs were calculated for all participants with employable age 65 and younger. Productivity losses due to early retirement and work absence days (only for those with regular full- or part-time employment) were taken into account to calculate indirect costs from a societal perspective using the human capital approach $[33,34]$. According to this approach, a year of disability 
is valued with the average labor costs, provided by the Federal Statistical Office [35] (35.904 $€$ in 2013).

Early retirement was considered for those who reported retirement due to health or other reasons. To assess costs caused by temporary work absence, participants were asked how many days they had been absent due to illness during the previous 12 months. Values greater than 208 days (number of actual working days in 2013 in Germany [36]) were corrected to $208(n=3)$. Each day of absence was valued with $172.45 €$, the quotient of the average labor costs and the actual working days.

\section{Statistical analysis}

Unadjusted means for utilizations and costs as well as the histograms of the two risk measures G-WTTR and H-WTTR were calculated. Additionally, the correlation coefficient of G-WTTR and H-WTTR was assessed using Pearson's correlation coefficient.

All regression models were performed separately for the two RA measures using the same functions and covariates to identify potential differences and similarities in the effect estimates of RAs on preventive and medical services and costs. Since we used the z-standardized version of the RA values in the regression analyses, all estimates can be interpreted as the effect on the outcome for a one SD increase in the independent variables GWTTR and H-WTTR .

In a first step, logistic regression models were applied to analyze the association of RAs with healthcare utilization and work absence. Second, participants who reported values greater than zero (users only) were then included in a generalized linear model with a zero-truncated negative binomial distribution and log-link function to evaluate the association between RAs and frequency of utilization. Finally, to examine the association of RAs with direct medical and indirect costs, we fitted gamma regression models with log-link functions using the procedure of generalized regression models (GLM). Use of this model was necessary to meet the demands of the typically skewed distribution of costs. We imputed a value of $1 €$ for all participants with zero direct $(n=289,15.9 \%)$ and indirect $(n=735,51.4 \%)$ costs as recommended by Barber et al. [37]. In line with previous literature, all models were adjusted for the exogenous determinants age, sex, and height [8].

Significance levels were set at the $5 \%$ level. Statistical analyses have been carried out with SAS software V.9.3 (SAS Institute, Cary, North Carolina, USA).

\section{Sensitivity analysis}

We performed a sensitivity analysis to identify the influence of the covariates included in the regression models. Anderson et al. [16] reported significant positive associations between risk aversion and behavioral health risks (smoking, alcohol consumption, and being overweight). Therefore, we extended the basic model by adding the following variables, which we considered to be additional potential confounders of RA and the outcomes of interest: social class, comorbidity, smoking status, alcohol consumption and physical activity.

\section{Results}

Table 1 presents the socio-demographic characteristics of the study sample. In the sample population, $52.6 \%$ of participants were female, the mean age was 56.5 (SD 9.5) years and mean height was $169.7(\mathrm{SD} 9.5) \mathrm{cm}$. Total mean annual direct costs were $1873 €$ (SD 6026) per participant. Mean annual indirect costs, which were only calculated for participants with employable age $\leq 65$ were $3938 €($ SD 10031) and were predominantly caused by

Table 1 Socio-demographic characteristics of the KORA FF4 sub-sample

\begin{tabular}{|c|c|}
\hline Characteristics & Total $(n=1823)$ \\
\hline Male & $864(47.4)$ \\
\hline Age (years) & $56.5 \pm 9.5$ \\
\hline Height (cm) & $169.7 \pm 9.5$ \\
\hline Social class index & $15.4 \pm 5.0$ \\
\hline \multicolumn{2}{|l|}{ Physical Activity } \\
\hline Active ( $\geq 1 \mathrm{~h}$ of sports per week) & $1097(60.2)$ \\
\hline Inactive (< $1 \mathrm{~h}$ of sports per week) & $726(39.8)$ \\
\hline \multicolumn{2}{|l|}{ Alcohol consumption } \\
\hline Low risk (women $\leq 12 \mathrm{~g}$, men $\leq 24 \mathrm{~g}$ p.d.) & $1267(69.5)$ \\
\hline Elevated risk (women $>12 \mathrm{~g}$, men $>24 \mathrm{~g}$ p.d.) & $555(30.5)$ \\
\hline \multicolumn{2}{|l|}{ Smoking status } \\
\hline Current smoker & $328(18.0)$ \\
\hline Former smoker & $708(38.8)$ \\
\hline Never smoker & $787(43.2)$ \\
\hline Hypertension ${ }^{a}$ & $580(31.9)$ \\
\hline Diabetes mellitus ${ }^{b}$ & $121(6.6)$ \\
\hline Angina Pectoris & $134(7.4)$ \\
\hline Stroke & $28(1.5)$ \\
\hline Cancer & $158(8.7)$ \\
\hline \multicolumn{2}{|l|}{ Risk attitude } \\
\hline G-WTTR & $4.46 \pm 2.21$ \\
\hline H-WTTR & $3.14 \pm 2.18$ \\
\hline \multicolumn{2}{|l|}{ Annual costs $(€)$} \\
\hline Direct costs & $1873 \pm 6026$ \\
\hline Indirect costs ${ }^{c}$ & $3938 \pm 10,031$ \\
\hline
\end{tabular}

data are $\mathrm{n}(\%)$ or mean \pm SD

G-WTTR: Willingness to take risk in general; H-WTTR: Willingness to take risk regarding health

${ }^{a} n=1821$ : two observations with missing value

${ }^{\mathrm{b}} n=1819$ : four observations with missing value

${ }^{c} n=1429$ : indirect costs only for persons with employable age $\leq 65$ years 
early retirement (74\%). Overall, $15.9 \%$ of all participants had no direct medical costs, whereas roughly half of the participants with employable age incurred no indirect costs in 2013. Detailed information on the mean frequency of utilization and the adapted unit costs for each direct and indirect cost category are provided in Additional file 1: S1.

\section{Descriptive analysis of the risk attitude variables}

The distributions of the two RA measures are displayed in Fig. 1. Mean values were 4.46 (SD 2.21) for G-WTTR and 3.14 (SD 2.18) for H-WTTR. The highest possible number 10 was chosen by less than $1 \%$ of all participants. This was true for both RA measures. Looking at the other side of the scale, roughly $4 \%$ stated a value of 0 for G-WTTR, and a much larger proportion of participants $(12.6 \%)$ choose the smallest value on the scale to indicate their H-WTTR. The values 5 and 2 were the modal responses of general and health WTTR, respectively. Pearson's correlation coefficient revealed a moderate positive linear relationship between the two measures with $r=0.40(\mathrm{p} .<0001)$. When adjusting for age and sex, the partial correlation coefficient remained almost unchanged with $r=0.37$ (p. <0001).

\section{Preventive services}

The odds ratios (OR) of general and health WTTR for the likelihood of utilizing preventive services are summarized in Table 2. Each effect estimate is based on a separate regression analysis with the dependent variable in the left column and either G-WTTR or H-WTTR as part of the regression function. We found that the probability of ever undergoing a medical check-up decreased with higher H-WTTR (OR 0.89, 95\% confidence interval
Table 2 Probability of using preventive services (ever) Logistic regression models, adjusted for age, sex and height

\begin{tabular}{llll}
\hline Dependent variable & Proportion (yes) & G-WTTR & H-WTTR \\
\hline & & OR [95\% Cl] & OR [95\% Cl] \\
Medical check-up & $56.6 \%$ & $1.02[0.93-1.12]$ & $0.89^{*}[0.81-0.98]$ \\
Screening (overall) & $88.5 \%$ & $0.91[0.77-1.06]$ & $0.94[0.81-1.09]$ \\
Skin cancer & $58.5 \%$ & $1.03[0.93-1.13]$ & $0.95[0.86-1.04]$ \\
Colon cancer & $61.0 \%$ & $0.95[0.85-1.05]$ & $0.93[0.84-1.03]$ \\
Breast cancer $^{\text {a }}$ & $78.6 \%$ & $0.92[0.77-1.10]$ & $0.95[0.80-1.13]$ \\
Cervical cancer $^{\text {a }}$ & $84.7 \%$ & $1.01[0.84-1.21]$ & $0.90[0.75-1.08]$ \\
Prostate cancer $^{\text {b }}$ & $60.5 \%$ & $0.96[0.82-1.12]$ & $0.87[0.75-1.01]$ \\
\hline
\end{tabular}

**significant at the $1 \%$ level/ * significant at the $5 \%$ level

G-WTTR: Willingness to take risk in general; H-WTTR: Willingness to take risk regarding health

a Only for women ( $n=959$ observations), adjusted for age and height

bonly for men ( $n=864$ observations), adjusted for age and height

(CI) 0.81-0.98). Considering all types of screening programs, women had a 9.55 times (general) or 9.67 times (health) higher odds to have ever participated in a screening program compared to men. When limiting the screening programs to skin cancer and colon cancer, which are practicable for both sexes, the effect estimates decrease but remain significant with women having had a 1.71 (general) or 1.67 (health) times higher probability of screening participation compared to men. Higher age was associated with a higher probability of participation except in the case of cervical cancer screening. Whereas the estimates for sex and age were significant in nearly all analyses, only a few significant associations between height and the utilization of preventive services were observed with the trend of higher probabilities for taller participants.
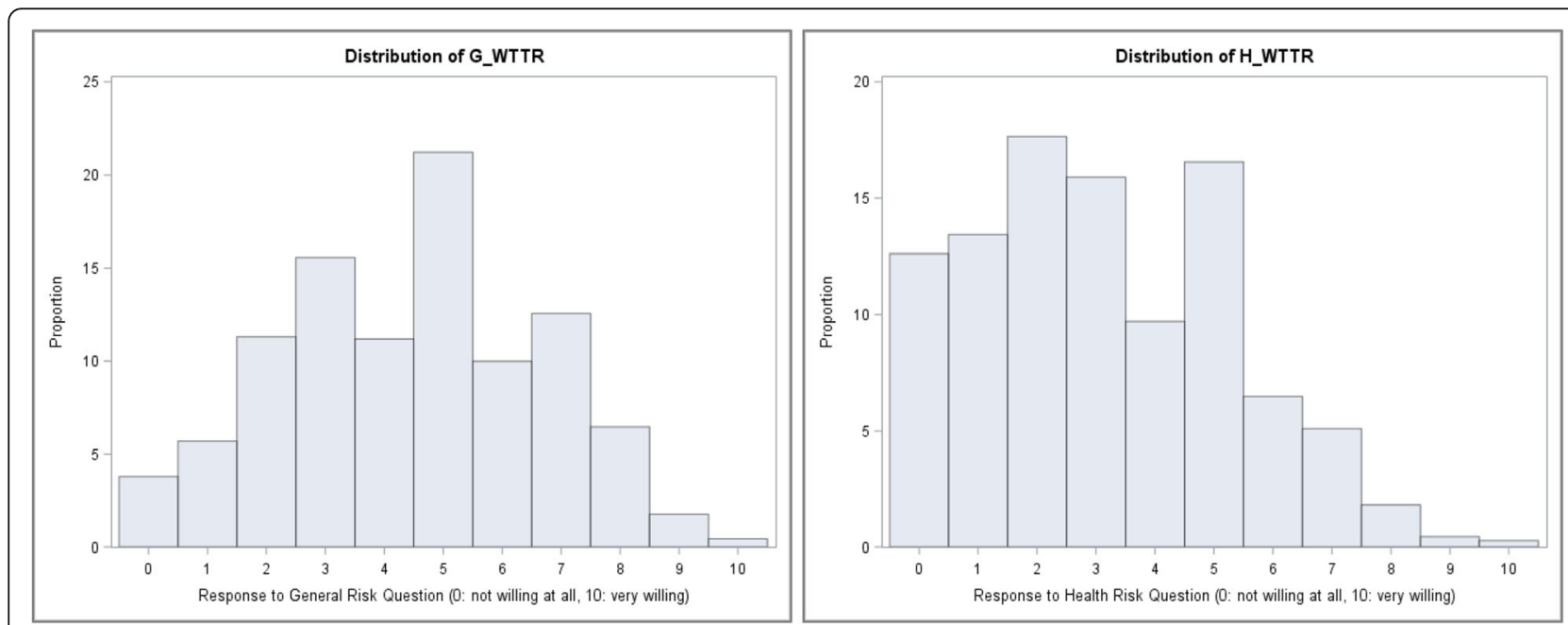

Fig. 1 Histogram of responses of G-WTTR and H-WTTR measured on an 11-point scale 


\section{Medical healthcare utilization}

Table 3 displays the ORs for the association of RAs with the probability of having any healthcare utilization, work absence days or early retirement. We found a significant association between H-WTTR and the probability of having at least one physician visit in the previous 3 months with an OR of 0.90 [95\% CI 0.81-0.99] for an increase in one SD in H-WTTR. A similar association for G-WTTR with trend $p<0.10$ was observed. Higher G-WTTR was associated with a decreasing likelihood of medication intake (OR 0.82, 95\% CI 0.74-0.91). The majority of ORs for the variable sex showed values greater than 1 indicating higher probabilities of utilization for women compared to men. We found positive associations between age and utilizations. We did not find significant associations between height and the outcomes except in the case of pharmaceutical use (OR 0.98, 95\% CI 0.97-1.00 for G-WTTR and H-WTTR).

The results of the zero-truncated negative-binomial regressions describing the associations between RAs and the frequencies of utilization given any utilization are summarized in Table 4. We found that an increase of one SD in G-WTTR lead to a $6 \%$ decrease in the number of physician visits among participants with at least one visit during the period examined. Among participants who reported an inpatient hospital stay, higher H-WTTR led to an increase in the number of inpatient hospital days (OR 1.15, 95\% CI 1.02-1.30). A one SD increase in G-WTTR was associated with a 1.32 (95\% CI 1.16-1.51) times higher number of alternative physician visits.

\section{Work absence days and early retirement}

Work absence days were reported by $54 \%$ of the 1079 individuals with full-time or part-time employment and $8 \%$ retired early with age $\leq 65$ years (see Table 5 ). Individuals with higher general or health WTTR were less likely to have at least one work absence day (OR 0.88, 95\% CI $0.77-0.99$ for G-WTTR and OR 0.88 , 95\% CI 0.78-0.99 for H-WTTR). The number of work absence days significantly decreased by $20 \%$ for a SD deviation increase in G-WTTR. We investigated a similar association between the number of work absence days and H-WTTR (OR 0.85, 95\% CI 0.77-0.94).

\section{Annual direct and indirect costs}

The associations of general and health WTTR with total annual direct and indirect costs are summarized in Table 6. We observed a negative association of G-WTTR on total indirect costs expressed by an estimate of 0.79 (95\% CI 0.69-0.90) for a one SD increase in G-WTTR. We did not find significant associations between RAs and the outcome direct costs. However, a trend was visible, indicating higher direct costs with increasing $\mathrm{H}$ WTTR. Regarding the covariates included in the gamma regression, an older age was associated with an increase in costs, whereas bigger height was associated with decreased costs.

\section{Results of the sensitivity analysis}

Estimates of the associations between the RAs and the likelihood of participating in a screening intervention or medical check-up remained unchanged when adapting the extended model, which included additional lifestyle and disease-specific variables as potential confounders. Gamma regressions for direct and indirect costs were performed using the same model. Similar to the results obtained from the small model, higher G-WTTR was associated with lower indirect costs. In addition, we observed a trend with $p<0.10$ concerning H-WTTR and total direct medical costs: a one SD increase of $\mathrm{H}$ WTTR was associated with $1.07(0.99-1.16)$ times higher total direct costs.

\section{Discussion}

This cross-sectional analysis of data from the populationbased KORA FF4 sample evaluated the association of RAs with the utilization of preventive and medical services as well as direct medical and indirect costs. RA was analyzed for both, willingness to take risk in general, and willingness to take risk regarding health. First, our results indicated a negative but mainly non-significant correlation between higher WTTR and participation in screening

Table 3 Probability of using medical services Logistic regression models, adjusted for age, sex and height

\begin{tabular}{lllll}
\hline Dependent variable & & Proportion (yes) & G-WTTR & H-WTTR \\
\hline & & & OR [95\% Cl] & $0.90^{*}[0.81-0.99]$ \\
Physician visit & (3 months) & $65.6 \%$ & $0.91[0.82-1.01]$ & $1.00[0.87-1.14]$ \\
Hospital treatment & $(12$ months) & $19.8 \%$ & $1.01[0.88-1.16]$ & $0.99[0.79-1.23]$ \\
Rehabilitation & $(12$ months) & $4.6 \%$ & $0.85[0.67-1.07]$ & $0.89^{*}[0.81-0.99]$ \\
Physical therapy & $(12$ months) & $32.6 \%$ & $0.96[0.87-1.06]$ & $0.93[0.79-1.09]$ \\
Alternative Physician & $(12$ months) & $9.9 \%$ & $0.96[0.82-1.13]$ & $0.82^{* *}[0.74-0.91]$ \\
Medication intake & (7 days) & $62.3 \%$ & & $0.95[0.86-1.05]$ \\
\hline
\end{tabular}

** significant at the $1 \%$ level/ * significant at the $5 \%$ level

G-WTTR: Willingness to take risk in general; H-WTTR: Willingness to take risk regarding health 
Table 4 Frequencies of utilization (users-only) Zero truncated negative-binomial regression models, adjusted for age, sex and height

\begin{tabular}{lllll}
\hline Dependent variable & Users & Frequency of utilization if used & G-WTTR & H-WTTR \\
\hline Number of & $(\mathrm{n})$ & (mean, unadjusted) & exp(estimate) [95\% Cl] & exp(estimate) [95\% Cl] \\
Physician visits & 1195 & $3.9(3.9)$ & $0.94^{*}[0.90-0.99]$ & $0.99[0.94-1.03]$ \\
Inpatient hospital days & 253 & $9.3(19.9)$ & $1.05[0.92-1.20]$ & $1.15^{*}[1.02-1.30]$ \\
Rehabilitation days & 84 & $24.5(19.3)$ & $0.92[0.81-1.04]$ & $0.95[0.84-1.07]$ \\
Physical therapies & 594 & $16.5(21.1)$ & $0.96[0.89-1.03]$ & $1.05[0.98-1.13]$ \\
Alternative physician visits & 180 & $4.2(5.4)$ & $1.32^{* *}[1.16-1.51]$ & $1.10[0.97-1.25]$ \\
Pharmaceuticals & 1135 & $2.6(2.0)$ & $0.97[0.93-1.02]$ & $0.97[0.93-1.01]$ \\
\hline
\end{tabular}

**significant at the $1 \%$ level $/ *$ significant at the $5 \%$ level

G-WTTR: Willingness to take risk in general; H-WTTR: Willingness to take risk regarding health

programs and preventive check-ups. Second, we found that individuals with higher WTTR were less likely to use the following healthcare services: physician visits, physical therapy (only for H-WTTR), and medication intake (only for G-WTTR). Finally, higher WTTR was associated with fewer work absence days.

The same set of RA questions has been included in previous waves of the German Socio-Economic Panel (SOEP), a representative panel survey of the resident adult population of Germany with approximately 11,000 private households and 22.019 individuals [38]. Based on this data, Dohmen et al. [8] reported mean values of 4.42 (SD 2.38) and 2.93 (SD 2.47) for general and health WTTR, respectively. As the paper focusses on the general measure, detailed information about the distribution of answers is only available for this risk measure. Similar to our results, the most frequent answer was 5 and roughly $7 \%$ of the SOEP participants chose the smallest possible number 0 . This similarity of results underlines the representativeness of the descriptive findings of the present analysis.

\section{Preventive services}

Turning to our results for the utilization of preventive services, our data could not confirm, in terms of statistically significant estimates, our hypothesis that higher WTTR is negatively correlated with participation in general. Only in the case of medical check-up, we found an increase in H-WTTR associated with an $11 \%$ decrease in the likelihood of ever having participated in such a check-up.

Comparison with prior research is limited as, to the best of our knowledge, this is the first study to analyze RAs in association with preventive services. The non-significant trend to a negative association found in general suggests that further tests of the hypothesis in other study settings with detailed data on preventive services seem warranted. In the present study, participation rates were found to be very high with nearly $90 \%$ reported participation in at least one screening intervention and above $60 \%$ for the single screening programs. Thus, voluntary participation in our study may have increased the selection of individuals specifically interested in health issues and preventive services.

\section{Healthcare utilization}

Our study hypothesis was that higher WTTR is associated with less healthcare utilization, featuring individuals less concerned with their health and possibly necessary care. The finding that higher WTTR was associated with a lower probability of having had a physician visit and a smaller number of physician visits given any reported utilization supports this. However, one might also consider a mechanism pointing in the opposite direction:

Table 5 Work absence and early retirement (sub-sample including working-age participants only)

\begin{tabular}{|c|c|c|c|}
\hline \multirow[t]{2}{*}{ Dependent variable } & & \multirow{2}{*}{$\begin{array}{l}\text { G-WTTR } \\
\text { exp(estimate) }[95 \% \mathrm{Cl}]\end{array}$} & \multirow{2}{*}{$\begin{array}{l}\text { H-WTTR } \\
\text { exp(estimate) }[95 \% \mathrm{Cl}\end{array}$} \\
\hline & Proportion yes / Mean frequency & & \\
\hline \multicolumn{4}{|c|}{ Probability of using medical services (logistic regression) } \\
\hline Work absence ${ }^{a}$ & $53.6 \%$ & $0.88^{*}[0.77-0.99]$ & $0.88^{*}[0.78-1.00]$ \\
\hline Early retirement ${ }^{\mathrm{b}}$ & $8.1 \%$ & $0.78[0.44-1.63]$ & $0.74[0.42-1.30]$ \\
\hline \multicolumn{4}{|c|}{ Frequencies of utilization ${ }^{c}$ (negative-binomial regression) } \\
\hline Work absence days & $14.7(27.1)$ & $0.80^{* *}[0.73-0.88]$ & $0.85^{* *}[0.77-0.94]$ \\
\hline
\end{tabular}

** significant at the $1 \%$ level/ * significant at the $5 \%$ level

G-WTTR: Willingness to take risk in general; H-WTTR: Willingness to take risk regarding health

${ }^{a} n=1079$ : work absence only for full-time and regular part-time employees

${ }^{b} n=138$ : early retirement only for pensioners with age $\leq 65$ years

${ }^{c} n=578$ 
Table 6 Annual direct medical and indirect costs Gamma regression models, adjusted for age, sex and height

\begin{tabular}{|c|c|c|}
\hline & $\begin{array}{l}\text { G-WTTR } \\
\text { exp(estimate) [95\% Cl] }\end{array}$ & $\begin{array}{l}\text { H-WTTR } \\
\text { exp(estimate) }[95 \% \mathrm{Cl}]\end{array}$ \\
\hline Total direct medical costs & $1.00[0.92-1.09]$ & $1.06[0.98-1.15]$ \\
\hline Total indirect costs ${ }^{a}$ & $0.79^{* *}[0.69-0.90]$ & $0.91[0.80-1.03]$ \\
\hline
\end{tabular}

Because of risky behavior, risk tolerant individuals might need medical treatment more often. Investigating this notion, we found higher H-WTTR to be associated with a higher number of hospital days given at least one hospital stay. While hospital diagnoses might help to identify relevant cases such admissions as a result of accidents, lack of respective data in our study limited further confirmation of this notion. Since a survey of historical risk attitude in a case-control design hardly seems possible, large cohort studies would be needed to test this notion.

Regarding alternative medicine, we found a positive association between higher G-WTTR and the number of alternative physician visits. This finding aligns with Sturm et al. [39], who evaluated the association of selfassessed risk seeking attitudes and the utilization of alternative medicine. Participants who considered themselves as more risk taking than the average person had a 2.47 times higher chance of visiting an alternative medicine provider.

Based on previous literature reporting correlations between WTTR and exogenous determinants, we included age, gender, and height as potential confounding variables in our analyses. As expected, we could investigate higher probabilities of utilization for older age. Interestingly, there was no significant association between age and the frequency of utilization given at least one reported utilization with the exception of use of pharmaceuticals. Here, older age was significantly associated with a greater number of pharmaceuticals used.

Although we could not observe significant associations between height and the probability or frequency of utilization, we found that bigger height was associated with lower total direct medical costs. A possible explanation might be an association between lower body height and elevated risk for cardiovascular disease and types of cancer, thus leading to increased healthcare costs $[40,41]$.

\section{Work absence}

To observe the entirety of sickness costs and consequential costs, we complemented the analyses of direct healthcare cost (e.g. physician visits and hospital stays) by components of indirect costs, namely work absence and early retirement. There is evidence that risk seeking individuals are more likely to become an entrepreneur, meaning that people with high RA are more likely to work on a self-employed basis [42, 43]. We assume this to be a possible explanation for our finding that higher RA was associated with a lower probability of having work absence days and also lower indirect costs. A second explanation could be that individuals with higher RA still attend to work even if they are not absolutely healthy. The extra risk regarding a possible aggravation of the state of health is accepted in this case. Thirdly, the specific type of occupation and the associated levels of physical activity have to be considered when interpreting these results. It is, of course, more difficult to show up for a physically stressful job when feeling sick than for a desk job. Application of the extended model to the cost regression analysis did not affect the estimates of RAs. This underlines the robustness of our results even when adjusting for additional variables such as socio economic status, lifestyle factors and the presence of certain diseases.

\section{General risk attitude or health risk attitude}

Dohmen et al. [8] identified the general risk question as the best "all round" predictor to measure people's willingness to take risks. However, the authors state that the domain-specific RAs should be preferred in the corresponding domains. For example, health RA is the best predictor for assessing risky health behavior such as smoking. This is also supported by Massin et al. [19], who studied the association of general practitioner's (GP) RA and their medical practices. The authors present a comparison of scales and lotteries as different measures for RA regarding the predictive power of the tools on GP's medical practices. A slightly modified version (addition of the word "daily") of the presented 11point scale was also included in the comparison. The authors conclude that the general measure is not suitable in predicting GP's medical practices and the domain-specific measures are to be preferred. Accordingly, we expected H-WTTR to be the best measure to analyze the association of RA with healthcare utilization and related costs. This was not confirmed by our results as the estimates for general and health WTTR only slightly differed in the effect size. 


\section{Strengths and limitations}

To the best of our knowledge, this is the first study to analyze preventive and medical healthcare utilization, work absence and costs in association with individuals' RAs. We make use of a simple risk measure, which can be easily captured through questionnaires. In this way assessed RAs values represent actual behavior in paid lottery choice experiments very well, as shown by Dohmen et al. [8]. The study provides a comprehensive overview of the direct and indirect cost components and sheds light on the specific healthcare services whose degree of utilization is associated with individuals' RAs.

Several limitations need to be noted regarding the present study. Individuals' RAs were assessed at a single point in time. Therefore, it cannot be ruled out, that important events in the past may have influenced the RAs in either direction. Decker et al. [20] provide an overview of articles studying important events, which were found to influence RA. Additionally, Liebenehm et al. [44] and Sachs et al. [45] report changes in RAs over time and therefore advocate the time-variability of RAs. However, for the purpose of our study, which was to identify aspects of healthcare utilization associated with RAs in cross-section, the results should not be biased by the assumption. It should further be noted, that inclusion of the variable "parental education" as a potential confounder in the regression analyses was not possible as it was not assessed in the KORA FF4 study or any previous survey. Nevertheless, our results remain the same when adjusting for the variable social status, which might have a high correlation with parental education. Regarding the utilization of preventive services, attitudes to health risks caused due to the screening intervention (e.g. post-colonoscopy complications [46]) were not considered or included in the analyses and might be an additional factor influencing the decision whether to undergo a screening procedure.

The cross-sectional study design implies further limitations. Healthcare utilization was assessed by asking participants to provide information retrospectively. This method is generally seen to be vulnerable to recall bias. By adapting the abridged time horizons for the specific healthcare categories ( 1 week for pharmaceuticals, 3 months for physician visits and 12 months for hospital stays and rehabilitations), we tried to circumvent this problem, as recommended by Seidl et al. [47]. Furthermore, results may be biased by the composition of the study sample, as the FF4 study is the second follow-up of the baseline S4 study. Participation rates vary with $66 \%$ for S4, 80\% for the second follow-up F4 and 69\% for the present FF4 study. This so-called selection bias cannot be ruled out and is a general limitation of studies with voluntary participation. When interpreting results, the restricted generalizability has to be kept in mind.

\section{Conclusions}

In conclusion, we observed associations between RAs and the likelihood and frequencies of utilizing specific healthcare services in the KORA FF4 subsample and an overall trend indicating a negative correlation between higher WTTR and the participation in preventive services. Further research should be undertaken to analyze the assumption of the time stability of RAs. Therefore, longitudinal surveys with multiple assessments of RAs are necessary to evaluate possible long-term changes. From a methodological point of view, our results indicate that both RA measures, G-WTTR and H-WTTR, seem to be useful when analyzing RAs in association with healthcare utilization, and results do not differ considerably depending on the chosen measure. From a societal perspective, our results indicate that RAs explain part of the heterogeneity of healthcare utilization. Regarding preventive programs, our findings indicate that interventions such as information campaigns intended to increase participation rates in screening programs and medical check-ups might be more effective when targeted at specific RA groups. Overall, our results contribute to the aim of better understanding individual health decisions.

\section{Additional file}

Additional file 1: S1. Utilization of healthcare services and unit costs. (DOC $60 \mathrm{~kb}$ )

\section{Abbreviations \\ $\mathrm{Cl}$ : Confidence Interval; H-WTTR: Willingness to take risk regarding health; GLM: Generalized Linear Model; GP: General Practitioner; G- WWTR: Willingness to take risk in general; KORA: Cooperative Health Research in the Augsburg Region; OR: Odds Ratio; RA: Risk attitude; SD: Standard Deviation; SOEP: The German Socio-Economic Panel; WIDO: AOK Research Institute; WTTR: Willingness to take risk}

\section{Acknowledgments \\ The authors would like to thank the field staff in Augsburg who were involved in conducting the studies, the team at the Helmholtz Zentrum München for data management and all attendees for their participation in the KORA survey.}

\footnotetext{
Authors' contributions

$J$ performed the statistical analysis, interpreted the data and drafted the manuscript. BS contributed with conceptual and methodological support, and commented on drafts of the paper.

MW contributed with methodological and statistical support in conducting the study, and commented on drafts of the paper. JW contributed to the research design and the empirical methods used, and commented on the manuscript from an econometric perspective. SW was involved in data interpretation, contributed to the manuscript with economic expertise and commented on the manuscript. AP is the main coordinator of the KORA study in which the data was collected, approved the research project and assured quality in the conduct of the survey. $\mathrm{RH}$ was involved in the coordination of the KORA study and contributed by integrating the research in the KORA study and data processing, and commented on drafts of the paper. RL contributed to the research design, conceptualized the paper, interpreted the data and commented on drafts of the paper. All authors critically read and approved the final version of the manuscript.
} 


\section{Funding}

The KORA research platform (KORA, Cooperative Research in the Region of Augsburg) was initiated and financed by the Helmholtz Zentrum MünchenGerman Research Center for Environmental Health, which is funded by the German Federal Ministry of Education and Research and by the State of Bavaria.

\section{Availability of data and materials}

The full dataset supporting the conclusions of this article is available upon request and application from the Cooperative Health Research in the Region Augsburg (KORA; https://www.helmholtz-muenchen.de/kora/ueber-kora/ index.html).

\section{Competing interests}

None of the authors has any conflicts of interest to disclose.

\section{Author details}

${ }^{1}$ Helmholtz Zentrum München, German Research Center for Environmental Health $(\mathrm{GmbH})$, Institute of Health Economics and Health Care Management, Ingolstaedter Landstr 1, 85764 Neuherberg, Germany.

${ }^{2}$ Ludwig-Maximilians-Universität München, Institute for Medical Informatics, Biometry and Epidemiology, Marchioninistr 15, 81377 Munich, Germany. ${ }^{3}$ Department of Economics, Ludwig-Maximilians-Universität München, Ludwigstr 33, 80539 Munich, Germany. ${ }^{4}$ ifo Institute - Leibniz Institute for Economic Research at the University of Munich, Poschingerstr 5, 81679 Munich, Germany. ${ }^{5}$ Helmholtz Zentrum München, German Research Center for Environmental Health $(\mathrm{GmbH})$, Institute of Epidemiology, Ingolstaedter Landstr 1, 85764 Neuherberg, Germany. ' Ludwig-Maximilians-Universität München, Munich Center of Health Sciences, Ludwigstr 28 RG, 80539 Munich, Germany.

Received: 8 April 2019 Accepted: 21 August 2019

Published online: 30 August 2019

\section{References}

1. Weber EU. Risk attitude and preference. Wiley Interdiscip Rev Cogn Sci. 2010;1(1):79-88

2. Donkers B, Melenberg B, Van Soest A. Estimating risk attitudes using lotteries: a large sample approach. J Risk Uncertain. 2001;22(2):165-95.

3. Weber EU, Blais AR, Betz NE. A domain-specific risk-attitude scale: measuring risk perceptions and risk behaviors. J Behav Decis Mak. 2002;15(4):263-90.

4. Figner B, Weber EU. Who takes risks when and why? Determinants of risk taking. Curr Dir Psychol Sci. 2011;20(4):211-6.

5. Rosen AB, Tsai JS, Downs SM. Variations in risk attitude across race, gender, and education. Med Decis Mak. 2003;23(6):511-7.

6. Bansback N, Harrison M, Sadatsafavi M, Stiggelbout A, Whitehurst DG Attitude to health risk in the Canadian population: a cross-sectional survey. CMAJ open. 2016:4(2):E284-91.

7. Sunde U, Dohmen T. Aging and preferences. J Econ Ageing. 2016;7:64-8.

8. Dohmen T, Falk A, Huffman D, Sunde U, Schupp J, Wagner GG. Individual risk attitudes: measurement, determinants, and behavioral consequences. J Eur Econ Assoc. 2011;9(3):522-50.

9. Jin J, He R, Gong H, Xu X, He C. Farmers' risk preferences in rural China: Measurements and determinants. Int J Environ Res Public Health. 2017:14(7):713.

10. Roth B, Trautmann ST, Voskort A. The role of personal interaction in the assessment of risk attitudes. J Behav Exp Econ. 2016;63:106-13.

11. Harrison JD, Young JM, Butow P, Salkeld G, Solomon MJ. Is it worth the risk? A systematic review of instruments that measure risk propensity for use in the health setting. Soc Sci Med. 2005;60(6):1385-96.

12. Butler S, Rosman A, Seleski S, Garcia M, Lee S, Barnes J, et al. A medical risk attitude subscale for DOSPERT. Judgm Decis Mak. 2012;7(2):189.

13. Vetter S, Heiss F, McFadden D, Winter J. Risk attitudes and Medicare part D enrollment decisions. Econ Lett. 2013;119(2):128-32.

14. Fraenkel $L$, Bogardus ST Jr, Wittink DR. Risk-attitude and patient treatment preferences. Lupus. 2003;12(5):370-6.

15. Prosser $L A$, Kuntz KM, Bar-Or A, Weinstein MC. The relationship between risk attitude and treatment choice in patients with relapsing-remitting multiple sclerosis. Med Decis Mak. 2002;22(6):506-13.

16. Anderson LR, Mellor JM. Predicting health behaviors with an experimental measure of risk preference. J Health Econ. 2008;27(5):1260-74.
17. Pearson SD, Goldman L, Orav EJ, Guadagnoli E, Garcia TB, Johnson PA, et al. Triage decisions for emergency department patients with chest pain. J Gen Intern Med. 1995;10(10):557-64.

18. Allison JJ, Kiefe Cl, Cook EF, Gerrity MS, Orav EJ, Centor R. The association of physician attitudes about uncertainty and risk taking with resource use in a Medicare HMO. Med Decis Mak. 1998;18(3):320-9.

19. Massin S, Nebout A, Ventelou B. Predicting medical practices using various risk attitude measures. Eur J Health Econ. 2018;19(6):843-60.

20. Decker S, Schmitz H. Health shocks and risk aversion. J Health Econ. 2016;50: 156-70.

21. Stigler GJ, Becker GS. De gustibus non est disputandum. Am Econ Rev. 1977;67(2):76-90.

22. Dohmen T, Lehmann H, Pignatti N. Time-varying individual risk attitudes over the great recession: a comparison of Germany and Ukraine. J Comp Econ. 2016:44(1):182-200.

23. Van Der Pol M, Hennessy D, Manns B. The role of time and risk preferences in adherence to physician advice on health behavior change. Eur J Health Econ. 2017;18(3):373-86.

24. Falk A, Becker A, Dohmen T, Enke B, Huffman D, Sunde U. Global evidence on economic preferences. Q J Econ. 2018;133(4):1645-92.

25. Cohen A, Einav L. Estimating risk preferences from deductible choice. Am Econ Rev. 2007:97(3):745-88.

26. Kowall B, Rathmann W, Stang A, Bongaerts B, Kuss O, Herder C, et al. Perceived risk of diabetes seriously underestimates actual diabetes risk: the KORA FF4 study. PLoS One. 2017;12(1):e0171152

27. Holle R, Happich M, Löwel H, Wichmann H, group MKs. KORA-a research platform for population based health research. Gesundheitswesen. 2005; 67(S 01):19-25.

28. Helmert U, Herman B, Joeckel K, Greiser E, Madans J. Social class and risk factors for coronary heart disease in the Federal Republic of Germany. Results of the baseline survey of the German cardiovascular prevention study (GCP). J Epidemiol Community Health. 1989;43(1):37-42.

29. Wacker M, Holle R, Heinrich J, Ladwig KH, Peters A, Leidl R, et al. The association of smoking status with healthcare utilisation, productivity loss and resulting costs: results from the population-based KORA F4 study. BMC Health Serv Res. 2013:13:278.

30. German Centre for Addiction Issues. Recommendations of the scientific committee of the German Center for Addiction Issues on limit values for the consumption of alcohol [http://uww.dhs.de/fileadmin/user_upload/pdf/dhs_stellungnahmen/ Grenzwerte Alkoholkonsum_Jul10.pdf] Accessed 08 February 2019.

31. Bock J, Brettschneider C, Seidl H, Bowles D, Holle R, Greiner W, et al. Calculation of standardised unit costs from a societal perspective for health economic evaluation. Gesundheitswesen. 2015;77(1):53-61 (Bundesverband der Arzte des Offentlichen Gesundheitsdienstes (Germany).

32. Research Institute of the AOK. Medicinal products [https://www.wido.de/ forschung-projekte/arzneimittel/] Accessed 08 February 2019.

33. Krauth C, Hessel F, Hansmeier T, Wasem J, Seitz R, Schweikert B. Empirical standard costs for health economic evaluation in Germany--a proposal by the working group methods in health economic evaluation. Gesundheitswesen. 2005;67(10):736-46 (Bundesverband der Arzte des Offentlichen Gesundheitsdienstes (Germany).

34. von der Schulenburg J-MG, Greiner W, Jost F, Klusen N, Kubin M, Leid R, et al. German recommendations on health economic evaluation - third and updated version of the Hanover consensus. Gesundheitsökonomie \& Qualitätsmanagement. 2007;12(05):285-90 [Deutsche Empfehlungen zur gesundheitsökonomischen evaluation-dritte und aktualisierte Fassung des Hannoveraner Konsens].

35. Federal Statistical Office. Compensation of employees, gross wages and salaries in Germany by Bundesland 1991 to 20162017 [http://www.vgrdl.de/NGRdL/tbls/ ?rev=RV2011\&lang=de-DE\#RV2011LA-GDP] Accessed 08 February 2019.

36. Fuchs J, Hummel M, Hutter C, Klinger S, Wagner S, Weber E, et al. Institute for Employment Research (IAB) Short Report: Records and challenges 2014.

37. Barber J, Thompson S. Multiple regression of cost data: use of generalised linear models. J Health Serv Res Policy. 2004:9(4):197-204.

38. Wagner GG, Frick JR, Schupp J. The German Socio-Economic Panel study (SOEP)-evolution, scope and enhancements. SOEPpaper No. 1; 2007.

39. Sturm R. Patient risk-taking attitude and the use of complementary and alternative medical services. J Altern Complement Med. 2000;6(5):445-8.

40. Nuesch E, Dale C, Palmer TM, White J, Keating BJ, van Iperen EP, et al. Adult height, coronary heart disease and stroke: a multi-locus Mendelian randomization meta-analysis. Int J Epidemiol. 2016;45(6):1927-37. 
41. Thrift AP, Gong J, Peters U, Chang-Claude J, Rudolph A, Slattery ML, et al. Mendelian randomization study of height and risk of colorectal cancer. Int Epidemiol. 2015;44(2):662-72.

42. Caliendo M, Fossen FM, Kritikos AS. Risk attitudes of nascent entrepreneursnew evidence from an experimentally validated survey. Small Bus Econ. 2009;32(2):153-67.

43. Cramer JS, Hartog J, Jonker N, Van Praag CM. Low risk aversion encourages the choice for entrepreneurship: an empirical test of a truism. J Econ Behav Organ. 2002;48(1):29-36.

44. Liebenehm S. Temporal stability of risk attitudes and the impact of adverse shocks—a panel data analysis from Thailand and Vietnam. World Dev. 2018. 102:262-74.

45. Sachs ML, Sporrong SK, Colding-Jørgensen M, Frokjaer S, Helboe P, Jelic K, et al. Risk perceptions in diabetic patients who have experienced adverse events: implications for patient involvement in regulatory decisions. Pharmaceut Med. 2017;31(4):245-55.

46. Reumkens A, Rondagh EJ, Bakker CM, Winkens B, Masclee AA, Sanduleanu S. Post-colonoscopy complications: a systematic review, time trends, and meta-analysis of population-based studies. Am J Gastroenterol. 2016;111(8): 1092-101.

47. Seidl H, Meisinger C, Wende R, Holle R. Empirical analysis shows reduced cost data collection may be an efficient method in economic clinical trials. BMC Health Serv Res. 2012;12(1):318.

\section{Publisher's Note}

Springer Nature remains neutral with regard to jurisdictional claims in published maps and institutional affiliations.

Ready to submit your research? Choose BMC and benefit from:

- fast, convenient online submission

- thorough peer review by experienced researchers in your field

- rapid publication on acceptance

- support for research data, including large and complex data types

- gold Open Access which fosters wider collaboration and increased citations

- maximum visibility for your research: over $100 \mathrm{M}$ website views per year

At BMC, research is always in progress.

Learn more biomedcentral.com/submissions 